\title{
Narcissistic Behavior in Adolescent Social Media Users
}

\author{
Perilaku Narsisme pada Remaja Pengguna Media Sosial
}

\author{
Kimmy Katkar \\ Universitas Semarang \\ kimmy@usm.ac.id \\ Dian Wishnu Brata \\ Universitas Semarang \\ dianwishnu@usm.ac.id
}

\author{
Anna Dian Savitri \\ Universitas Semarang \\ dsavie@usm.ac.id
}

\begin{abstract}
This research aims to determine the phenomenon of narcissistic behavior among adolescent social media users. Respondents who are the subjects in this study are adolescents aged 16 to 20 years who live in the Mranggen sub-district, Demak district who have more than three social media accounts that have been used for more than 1 year, and carry out activities on their social media every day. The method used in this research is a qualitative method with a phenomenological approach. Methods of data collection using interviews and documentation which are arranged based on the characteristics of narcissism. As for the data analysis technique that will be used is descriptive coding method. The results of the study show that the subject often shows a thing or situation that encourages other people to have a good impression by minimizing things that are negative or not good for themselves.
\end{abstract}

Keywords: narcissistic behavior, college student, student, social media

Abstrak

Penelitian ini bertujuan untuk mengetahui fenomena perilaku narsistik pada remaja pengguna media sosial. Responden yang menjadi subjek dalam penelitian ini adalah remaja berusia 16 hingga 20 tahun yang berdomisili di Kecamatan Mranggen Kabupaten Demak yang memiliki lebih dari tiga akun media sosial yang telah digunakan selama lebih dari 1 tahun, dan melakukan aktivitas di media sosial setiap hari. Metode yang digunakan dalam penelitian ini adalah metode kualitatif dengan pendekatan fenomenologi. Metode pengumpulan data menggunakan wawancara dan dokumentasi yang disusun berdasarkan karakteristik narsisme. Adapun teknik analisis data yang akan digunakan adalah metode pengkodean deskriptif. Hasil penelitian menunjukkan bahwa subjek sering menunjukkan suatu hal atau situasi yang mendorong orang lain untuk memiliki kesan yang baik dengan cara meminimalkan hal-hal yang bersifat negatif atau tidak baik bagi dirinya.

Kata kunci: perilaku narsistik, mahasiswa, media sosial

\section{PENDAHULUAN}

Maraknya penggunaan media sosial seperti Instagram, Twitter, WhatsApp, Facebook, Line, YouTube, dan Path telah mengubah perilaku manusia dari berbagai aspek, salah satunya dari aspek sosial yaitu berkurangnya interaksi, komunikasi dan sosialisasi secara langsung. Karena semua bisa tergantikan melalui dunia maya. Dengan adanya fitur-fitur seperti menulis status dan mengunggah foto maupun video. Individu bisa berbagi cerita yang positif maupun negatif dari fitur status atau caption dan bisa mem-posting foto ataupun video yang tujuannya adalah mendapatkan like dan komentar, seperti pujian. Semakin bertambahnya pengguna media sosial dan semakin seringnya intensitas menggunakan media sosial akan mengubah perilaku individu, sekaligus memicu gangguan-gangguan psikologis jika terlalu berlebihan dalam menggunakan media sosial (Hardika dkk, 2019). 
Hal ini sesuai dengan penelitian (Engkus dkk, 2017) mengenai perilaku narsis pada media sosial di kalangan remaja dan upaya penanggulangannya yang menunjukkan bahwa kategori tinggi perilaku narsisme di kalangan remaja cenderung menunjukkan perilaku membanggakan diri secara berlebihan, menganggap dirinya sebagai seseorang yang spesial dan unik, grandiosity dan lebih mementingkan diri sendiri. Perilaku narsisme yang muncul akan membuat remaja terobsesi untuk dapat memuaskan dorongan-dorongan yang ada pada dirinya dalam segi materi, kemampuan, kecantikan atau ketampanan yang ada pada diri remaja pelajar di Kawasan Bandung Timur.

Dampak positif media sosial adalah bisa meningkatkan kebahagiaan dan mengurangi tingkat stres pada penggunanya, jika individu mampu mengontrol rasa cemburu atau iri hati. Dampak negatif yang timbul adalah kemarahan, jika individu tidak mampu mengontrol dirinya. Hal ini sesuai oleh (Izzati dan Irma, 2018) mengenai perilaku narcissistic pada pengguna Instagram di kalangan mahasiswa Universitas Serambi Mekkah yang menunjukkan bahwa Narcisissitic positif adalah informan menjadikan media Instagram sebagai pengalihan atau pelarian dari rutinitas dan masalah serta pelepasan emosi.

Hal ini sesuai dengan pernyataan subjek ketika posting sebuah foto atau upload status jika mendapatkan like dalam jumlah banyak maka dapat menjadikan hiburan tersendiri saat merasa lelah dan stres. Perilaku narsisme pada remaja pengguna media sosial yang sering terlihat adalah foto selfie di tempat yang instagramable, posting sebuah video atau status yang digunakan untuk menunjukkan siapa dirinya serta kondisi terbarunya yang kemudian dibagikan secara bebas kepada pengguna lainnya secara leluasa. Setiap foto-foto atau video yang di-upload merupakan foto atau video terpilih yang akan menunjukkan sisi terbaik dari dirinya. Sehingga menampilkan hidup yang mereka miliki terlihat selalu baik, ideal dan sempurna dengan tujuan mendapatkan pujian, apresiasi dan tidak direndahkan orang lain serta untuk menumpang popularitas agar dianggap tidak ketinggalan zaman oleh teman-temannya (Purnamasari dan Agustin, 2018).

Hal ini di dukung oleh (Setiasih dan Puspitasari, 2015) mengenai kebutuhan remaja untuk mengirim foto atau video di Instagram yang menunjukkan bahwa salah satu karakteristik remaja adalah suka menonjolkan dirinya sendiri dalam lingkungan. Hal-hal yang ditampilkan pada lingkungan biasanya adalah sisi baik individu, hal ini dilakukan agar remaja dapat diterima oleh lingkungan sosial dan memperoleh hubungan pertemanan atau dapat menjalin relasi.

\section{METODE}

Tipe penelitian yang digunakan adalah metode kualitatif dengan pendekatan fenomenologi yang bertujuan untuk mendeskripsikan perilaku narsisme pada remaja pengguna media sosial. Metode yang dipakai untuk mengumpulkan data adalah dengan menggunakan metode wawancara dan dokumentasi yang disusun berdasarkan ciri-ciri narsisme dari DSM-V (APA, 2012). Teknik analisis data yang digunakan adalah pengkodean deskriptif di mana peneliti hanya meringkas pesan dari sebuah bagian kecil data kualitatif dalam sebuah kata atau frasa pendek (Saldana, 2009). Sedangkan untuk kredibilitas data dengan memakai triangulasi. Peneliti hanya menggunakan dua cara yang disesuaikan dengan tujuan penelitian, dua cara tersebut adalah sebagai berikut:

1. Membandingkan data hasil pengamatan dengan data hasil wawancara.

2. Membandingkan apa yang dikatakan orang lain dengan apa yang dikatakan subjek secara pribadi. 


\section{HASIL DAN PEMBAHASAN}

Hasil

Bagi kedua subjek media sosial adalah tempat yang bisa digunakan untuk memperkenalkan diri kepada masyarakat luas dengan harapan mendapat banyak pujian lewat postingan atau unggahan di media sosial. Dengan media sosial subjek bebas mengekspresikan segala perasaan yang sedang dialami dan dengan mudahnya bisa mengakses beragam informasi dan hiburan dari berbagai belahan di dunia. Merasa dirinya berbeda dari orang lain karena kemampuan yang dimiliki membuat subjek AV merasa bangga dan sering kali menunjukkan kemampuannya kepada teman-teman lewat unggahan status di WhatsApp dan Facebook (KB/S1/W3/B.120-123). Tujuannya adalah agar teman-temannya tahu akan kelebihan yang dimiliki subjek AV (KB/S1/W3/B.146-155). Begitu pula dengan subjek SD yang sering kali memperlihatkan kelebihan-kelebihannya dengan mengunggah status di WhatsApp dan story di Instagram. Tujuan dari menunjukkan kemampuan yang dimiliki adalah ingin membuat orang lain termotivasi agar bisa meniru hal-hal positif yang ada pada dirinya (KB/S2/W2/B.250-257).

Subjek AV mempunyai kelebihan masing-masing yang tidak semua temannya mempunyainya begitu pula dengan kekurangan (KB/S1/W3/B.277-293). Hal yang sama dinyatakan oleh subjek SD di mana dirinya menyadari bahwa setiap orang mempunyai kelebihan dan kekurangannya masing-masing di mana kekurangan tersebut hanya orang terdekatnya saja yang tahu (KB/S2/W2/B.356-366). Kedua subjek meminimalisasi akan kekurangan-kekurangan yang ada pada dirinya dengan jarang sekali memperlihatkan kekurangannya dengan menonjolkan kelebihan yang dimiliki.

Pada subjek AV, merasa dirinya tampan sehingga membuat subjek merasa percaya diri untuk selalu posting foto atau membuat status di Instagram, Facebook, maupun WhatsApp tentang dirinya dalam berbagai momen. Termasuk ketika berada di tempat yang bagus dan sering dikunjungi (KB/S2/W2/B.360-361). Sedangkan pada subjek SD, lebih sering membuat status di WhatsApp, Instagram dan membuat quote di Twitter terkait keberhasilan-keberhasilan akademik yang sudah tercapai (KB/S2/W2/B.410-420). Ketika menjalin hubungan sosial dengan teman sebayanya, subjek AV lebih memilih bergaul dengan teman yang tidak suka memanfaatkan orang lain dan bisa diajak tukar pendapat demi kemajuan bersama (KB/S1/W3/B.433-436). Sedangkan pada subjek SD lebih memilih bergaul dengan teman yang memiliki hobi dan minat yang sama (KB/S2/W2/B.512-520).

Berdasarkan hasil dokumentasi pada beberapa akun media sosial kedua subjek, menunjukkan bahwa karakteristik individu dikatakan narsisme sesuai dengan kedua subjek. Hasil penelitian tersebut berupa posting-an foto dan status disertai dengan caption yang dibagikan kepada followers atau temannya. Adapun foto tersebut sebagai berikut:

1. Melebih-lebihkan kemampuan yang dimiliki

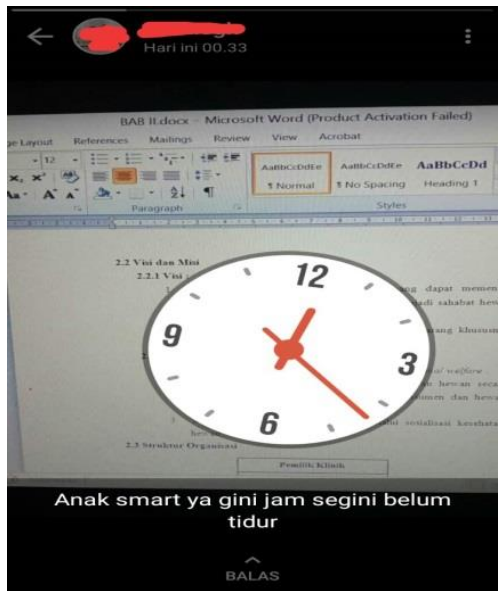

Narcissistic Behavior in Adolescent Social Media Users

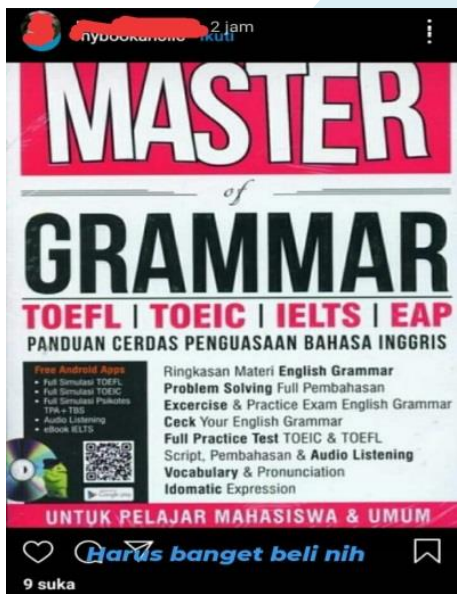

14
K. Katkar, D. W. Brata, A. D. Savitri

Universitas Semarang 
2. Memiliki rasa iri terhadap orang lain atau menganggap orang lain iri kepadanya
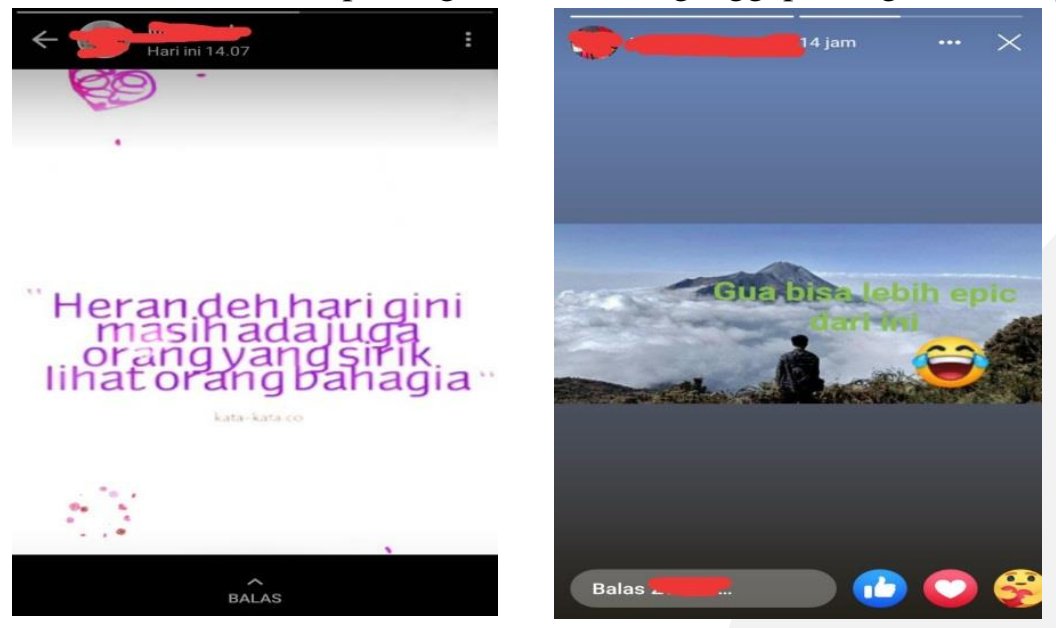

\section{Pembahasan}

Di dalam pembahasan ini, hasil yang di dapat peneliti akan dibahas dengan menggunakan teori dramaturgi dari Goffman yang memandang bahwa kehidupan manusia itu sebagai sebuah panggung sandiwara, di mana manusia memainkan peran yang ia dapat sebaik mungkin agar penonton mampu mengapresiasi dengan baik pementasan tersebut. Peran di sini adalah kehidupan nyata dari para subjek di mana munculnya perilaku narsisme ini terbentuk agar orang lain melihat diri subjek sebagai orang yang sempurna, baik, cerdas, paling menarik dan kompeten. Menonjolkan berbagai macam kelebihan yang dimiliki dengan sedikit menunjukkan rasa sakit, sedih yang dialami adalah suatu bentuk peran di dunia ini. Tujuan dan harapan kedua subjek adalah ingin menampilkan diri mereka sebaik mungkin agar menarik perhatian dan mendapatkan banyak pujian. Sejauh ini topeng telah membantu untuk membentuk suatu konsep sesuai keinginan yang bisa dibentuk dari diri kita sendiri, diri yang kita inginkan. Pada akhirnya konsep tentang peran kita yang sebenarnya menjadi kodrat kedua dan menjadi bagian dari sebuah kepribadian (Goffman, 1971).

Sesuai dengan pandangan Goffman di atas bahwa kedua subjek dapat mengambil peran dan memilih topeng yang dikenakan untuk membentuk suatu penilaian yang akan ia bentuk dan menyatu dalam dirinya. Dalam membentuk panggung ini ada hal-hal yang berkaitan untuk menunjang penampilan mereka pada saat berada di panggung. Seperti halnya subjek AV, yang terlihat memikirkan apa yang ia kenakan, di mana tempatnya, tujuannya apa agar dapat menarik perhatian dan mendapat banyak pujian dari teman-temannya ketika berada di suatu tempat tertentu. Pada subjek AV untuk menunjukkan status sosialnya tersebut ditunjukkan melalui posting-an atau status di media sosial yang dimiliki saat ia berada di sebuah tempat yang menarik seperti di sebuah kafe dengan memperlihatkan foto-fotonya yang instagramable di mana kafe tersebut adalah kafe yang cukup mahal untuk sekedar nongkrong saja. Selain itu subjek juga sering mengunggah status di WhatsApp terkait saat dirinya berada di gym yang mana dalam fotonya memperlihatkan secara jelas bentuk badannya.

Sedangkan pada subjek SD yaitu dengan memperlihatkan kemampuan-kemampuan dan status sosialnya kepada orang lain serta di dukung oleh berbagai macam status di WhatsApp-nya terkait latar belakang keluarga maka akan mendapat pengakuan dan pujian dari masyarakat. Hal yang sama dinyatakan oleh Beck dkk (dalam Halgin \& Whitbourne, 2010) bahwa narsisme mencakup hal-hal yang dipandang dari segi gaya hidup yang dijalani termasuk menunjukkan status sosial. Sesuai dengan hasil dokumentasi, subjek AV sering posting foto dan membuat status akan usaha yang sedang dirintisnya mulai berkembang dan mendapat untung yang cukup banyak. 
Selain itu subjek sering posting foto yang digunakan untuk status di WhatsApp akan benda-benda dengan harga cukup mahal yang dibelinya.

Menurut Buffardi dkk (2008), ada beberapa ciri individu narsistik dalam media sosial yaitu tingkat aktivitas sosial yang lebih tinggi dalam komunitas online daripada offline dan banyak posting-an atau status yang memperlihatkan kemampuan dalam berbagai aspek. Sesuai dengan hasil wawancara kepada kedua subjek yang menyatakan bahwa kemampuan itu perlu ditunjukkan kepada orang lain dengan maksud orang lain yang melihatnya bisa terinspirasi. Kedua subjek menyatakan bahwa mempunyai teman lebih banyak di dunia maya dibandingkan dunia riil. Berdasarkan kesamaan hobi dan minat, kedua subjek merasa lebih mudah mendapatkan teman lewat berbagai macam media sosial karena bisa menjangkau hingga seluruh dunia dan tidak terbatas.

Dengan seringnya mendapat pujian dari teman-temannya maka akan lebih mendorong kedua subjek untuk tetap eksis dengan berbagai macam kemampuan yang dimiliki. Hal ini sesuai dengan (Ummul et al, 2019) narsistik individu akan meningkat jika banyaknya orang lain melihat atau memuji suatu hal yang di-posting-nya. Individu yang mengalami gangguan narsistik akan selalu fokus pada dirinya sendiri. Pendapat Goffman (Sabekti et al, 2019) menggambarkan bahwa individu sering melebih- Kedua subjek menggunakan media sosial untuk menunjukkan diri mereka kepada orang lain dengan memperlihatkan segala kelebihan yang dimiliki karena subjek merasa dirinya unik mempunyai sesuatu yang beda dari orang lain kebanyakan dan lebih tahu akan suatu hal tertentu dibandingkan dengan teman-temannya. Dengan cara mengekspresikannya lewat media sosial, maka penonton yang melihatnya akan memberi penilaian terhadap subjek dari apa yang di-posting.

\section{PENUTUP}

Kedua subjek sering memperlihatkan suatu hal atau situasi yang mendorong agar orang lain memiliki kesan yang baik-baik dengan meminimalkan hal-hal yang negatif atau kurang baik untuk dirinya sendiri. Tujuan dari perilaku narsisme ini adalah agar mendapatkan pujian, perhatian dari orang lain, menunjukkan status sosial, mendapatkan citra yang baik dan menunjukkan berbagai macam kelebihan yang dimiliki. Seperti merasa paling tahu akan suatu hal dan paling terbaik di antara teman-temannya.

\section{DAFTAR PUSTAKA}

American Psychiatric Association. (2012). Diagnostic and Statistical Manual of Mental Disorders, Fifth Edition. Washington: American Psychiatric

Buffardi, Laura E. \& Campbell, W. (2008). Narcissism and social networking web sites. Personality and Social Psychology Bulletin. Vol. 34

Engkus, Hikmat \& Saminnurahmat K. (2017). Perilaku Narsis Pada Media Sosial Di Kalangan Remaja Dan Upaya Penanggulangannya. Jurnal Penelitian Komunikasi. Vol. 20. No. 2. Hal. 121-134

Goffman, E. (1971). The Presentation Of Self In Everyday Life. University of Edinburgh Social Science Research Center

Halgin, R. P., \& Whitebourne, S. K. (2010). Psikologi Abnormal: Perspektif Klinis Pada Gangguan Psikologis. Jakarta: Salemba Humanika

Hardika, J. Noviekayati, I \& Saragih.S. (2019). Hubungan Self-Esteem Dan Kesepian Dengan Kecenderungan Gangguan Kepribadian Narsistik Pada Remaja Pengguna Sosial Media Instagram. Jurnal Psikosains. Vol. 14. No.1. Hal. 1-13

Izzati, F \& Irma, A. (2018). Perilaku Narcissistic Pada Pengguna Instagram Di Kalangan 
Mahasiswa Universitas Serambi Mekkah. Jurnal Ilmiah Mahasiswa FISIP Unsyiah. Vol. 3. No. 2

Purnamasari, A \& Agustin, V. (2018). Hubungan Citra Diri Dengan Perilaku Narsisisme Pada Remaja Putri Pengguna Instagram Di Kota Prabumulih. Jurnal Psibernetika. Vol. 11. No. 2. Hal. 115-132

Sabekti, R., Yusuf, A \& Pradanie, R. (2019). Aktualisasi Diri Dan Kecenderungan Narsisme Pada Remaja Akhir Pengguna Media Sosial. Jurnal Keperawatan Jiwa. Vol. 1. No. 1

Saldana, J. (2009). The Coding Manual for Qualitative Researchers. London: Sage

Setiasih \& Puspitasari, F. I. (2015). Kebutuhan Remaja Untuk Mengirim Foto Atau Video Di Instagram. Jurnal Psikologi Ulayat. Vol. 2. No. 2. Hal. 461- 472

Umul, S., Fahli, Z \& Darmawati. (2019). Fenomena Narsistik di Media Sosial Sebagai Bentuk Pengakuan Diri. Jurnal Bimbingan Konseling Islam. Vol. 2. No.1. Hal. 34-43 